\title{
The double burden household in sub-Saharan Africa: maternal overweight and obesity and childhood undernutrition from the year 2000: results from World Health Organization Data (WHO) and Demographic Health Surveys (DHS)
}

Janet M Wojcicki

\begin{abstract}
Background: Previous studies have characterized an increasing trend of double burden households, or households with individuals experiencing both undernutrition and obesity, in countries undergoing a nutrition transition. Although most prior studies indicate the prevalence of double burden households is highest in middle-income countries, there is some support for an increase in double burden households in sub-Saharan African countries as well.

Method: Using data from the Demographic Health Surveys (DHS) and the World Health Organization (WHO), the prevalence of double burden households in sub-Saharan African countries was calculated and the associations between prevalence of overweight/obese adults and underweight, stunted and wasted children were evaluated at the country and household (DHS only) levels. Restricted analyses and frequencies were calculated using urban-only datasets. Surveys from 28 African countries were available using WHO data and 26 from the DHS surveys. Only surveys that were conducted after 2000 were included in analyses.

Results: Using the WHO datasets, there were inverse associations between the prevalence of overweight and obesity in adults and underweight, stunting and wasting in children. Correspondingly, there were positive associations between adult underweight and child underweight, stunting and wasting. These associations were not significant in a smaller sample size using urban-only surveys. The prevalence of double burden households in DHS datasets was low: under 5 percent for obese mothers and underweight, stunted or wasted child pairs with a slightly higher percentage for overweight mothers and children with undernutrition. Restricting the analysis to urban only populations did not increase the frequencies of double burden households significantly.

Conclusion: There was a low prevalence of double burden households in recent data from sub-Saharan Africa. Countries that have a high prevalence of child undernutrition correspondingly have a high prevalence of adult underweight and low prevalence of adult overweight and obesity.
\end{abstract}

Correspondence: wojcickij@peds.ucsf.edu

Department of Pediatrics, University of California, 500 Parnassus Avenue

MU4E, San Francisco, CA 94134-0136, USA 


\section{Background}

\section{Overweight and obesity and malnutrition globally}

The number of overweight and obese women has continued to increase internationally including in low-income countries such as those in sub-Saharan Africa [1]. Meanwhile, undernutrition is associated with one third to one half of the deaths of children under 5 years of age globally [2]. In sub-Saharan Africa, 28\% of children under 5 years of age are moderately or severely underweight [3] with $38 \%$ of children under five stunted [4]. These numbers have not significantly changed since 1990 when $32 \%$ of children under 5 were moderately or severely stunted [4]. Meanwhile global obesity prevalence has doubled since 1980 [1]. In a study of 7 African countries (Burkina Faso, Ghana, Kenya, Malawi, Niger, Senegal and Tanzania), the prevalence of urban adult overweight and obesity increased approximately 35\% from 1992 to 2005 [5]. Similarly, the prevalence of overweight and obesity among preschool children is expected to increase from $8.5 \%$ in 2010 to $12.7 \%$ in 2020 [6].

\section{Double -burden households}

Recent studies have found an increasing trend of 'dual burden' or double burden households, households that have both underweight or stunted and overweight/obese persons $[7,8]$. In particular, countries that are in the middle range of gross national product (GNP) have been found to have the highest prevalence of dual burden homes, most commonly with stunting and/or underweight among children coexisting with an overweight or obese mother $[7,8]$. In studies conducted in Brazil, China, Indonesia, United States and Vietnam, dual burden households were more likely to be urban and among the highest income levels in contrast with underweight-only households. However, double burden homes were not easily distinguished from overweight-only households [7]. The nutrition transition, a change in activity levels and dietary patterns that happens when a country passes to higher levels of economic development facilitating the availability of cheaper energy dense and nutrient poor food stuffs, could be responsible for the co-existence of obesity and undernutrition in the same homes [8-10]. Meanwhile, however, some studies from sub-Saharan Africa have found a low prevalence of double burden households [8-10].

In a report of data from the Demographic and Health surveys of 23 sub-Saharan African countries, African countries surveyed had less than $10 \%$ of households with stunted child-overweight mother pairs with the exception of Egypt, which had 14\% [9]. A study from urban Benin (Cotonou), found a higher prevalence (16.2\%) of households with concurrent maternal overweight/obesity and child stunting or child wasting [10]. Meanwhile, the majority of the Demographic and Health surveys in the study by Garrett and Ruel [9] were from the period of
1991-1998. It is possible that in the last 10-20 years, the prevalence of double burden households has increased significantly in sub-Saharan African countries, particularly in urban areas that have had more of a nutrition transition. The prevalence of stunted child-overweight mothers was higher in urban African areas in comparison with rural ones because of the fewer number of women who are overweight/obese in rural areas [9].

In a more recent study using Demographic Health Survey data from the early 2000s from North Africa, sub-Saharan Africa, Asia and Latin America, Jehn and Brewis [8] found that low levels of maternal education, working in agriculture, living in urban areas, increased siblings in the household and relative poverty were associated with increased risk of dual burden households. However, Jehn and Brewis [8] found that the overall prevalence of dual burden households was low in the African countries surveyed, particularly the prevalence of maternal overweight and child underweight homes $(<5 \%$ of households). Jehn and Brewis [8] examined only a limited number of surveys from sub-Saharan African countries and used data collected in the early 2000's. Since the time of publication, DHS has released a new series of surveys (DHS V); many conducted post 2005 that are included in the analysis below.

In this review of double burden households in subSaharan Africa, we assess both the association between maternal body mass index (BMI) category and child undernutrition using country level data (World Health Organization Survey Data from the Nutrition Databases) and the prevalence of double burden households using household level data as described below (DHS data). In contrast with previous studies, we evaluate associations using post-2000 data, with a particular emphasis on data collected after 2005.

\section{Methods}

Two different survey sets were used to evaluate the prevalence of double burden households and estimate the possible association between maternal overweight/obesity and child undernutrition. These datasets were publically available and no unique identifiers were available. The WHO surveys were included in this analysis given the large number of surveys conducted in each country. However, as the data were not collected at the household level, it was not possible to assess the prevalence of double burden households but only evaluate the country-level associations between adult BMI category and child undernutrition. For WHO data, in some case women and in other cases combined women and men data are available. The Demographic Health Surveys were also included in this study so as to be able to assess the prevalence of double burden households in sub-Saharan African countries using household level data, albeit using a smaller number of surveys per 
country than those available in the WHO database. The specific datasets and methods used are described in detail below.

\section{WHO database}

To estimate the possible relationship between maternal overweight/obesity and child stunting and underweight, we used the World Health Organization's (WHO) Global Database on Child Growth and Malnutrition and the WHO's Global Database on Body Mass Index to assess a possible correlation between frequencies of adult obesity (a body mass index $(\mathrm{BMI}) \geq 30 \mathrm{~m} / \mathrm{kg}^{2}$ ), overweight (BMI $\geq 25 \mathrm{~m} / \mathrm{kg}^{2}$ ), underweight (BMI $<18.5 \mathrm{~m} / \mathrm{kg}^{2}$ ) and child stunting (having a height-for-age $\mathrm{Z}$ score $<-2$ standard deviations (SD) below the international reference median or $<-3 S D$ for severe stunting, underweight (having a weight-for-age $Z$ score $<-2$ SD or $<-3 S D$ for severe underweight, wasting (having a weight-for-height $Z$ score or a BMI-for-age $\mathrm{z}$-score $<-2 \mathrm{SD}$ or $<-3 \mathrm{SD}$ for severe wasting), overweight (having a BMI-for-age $z$-score $>+2$ $\mathrm{SD}$ ) and obesity (BMI-for-age z score $>+3 \mathrm{SD}$ ). Data from the following 28 sub-Saharan Africa countries were included from the WHO databases: Benin, Burkina Faso, Cameroon, Chad, Congo, Democratic Republic of the Congo, Eritrea, Ethiopia, Gabon, Ghana, Kenya, Lesotho, Liberia, Madagascar, Malawi, Mali, Mauritania, Morocco, Mozambique, Namibia, Niger, Nigeria, Rwanda, Sierra Leone, Swaziland, Uganda, Zambia, Zimbabwe. WHO compiles data collected from national and sub-national surveys $[11,12]$. We restricted all analyses to surveys conducted after the year 2000 in the two databases [11,12]. Children in the WHO datasets are under 5 years of age.

The WHO Global Database on Body Mass Index combined BMI results from men and women and included the use of 3,169 surveys and smaller studies from 28 countries (2,642 national and 527 subnational surveys). The criteria WHO uses for surveys included in its database is a defined population-based sampling frame and a probabilistic sampling procedure involving at least 400 children [13]. Using the results of BMI from women only, the restricted sample included 1,432 surveys and excluded those samples that had combined results for adults of both sexes. The WHO's Global Database on Child Growth and Malnutrition had a smaller number of surveys on child anthropometrics $(n=1,948)$ but we still used the same number of African countries listed above $(\mathrm{n}=28)$.

Furthermore, we conducted a smaller subset analysis of urban surveys only with data from 23 countries, which included 89 surveys of which 58 were women only. Means and standard deviations were calculated for each country for percentage of BMI in the overweight and/or obese category and child anthropometrics using Stata 13.0. Linear regression was subsequently used to evaluate relationships between mean frequencies of adult overweight/obesity and mean levels of stunting, wasting and underweight by country.

Sampling weights for the different surveys were not provided by WHO. Subsequently, analyses were restricted to adult female BMI numbers only and then to surveys conducted only among urban residents. In the analyses that included all adults and women only, the sample size was $\mathrm{n}=28$ African countries for both adults and only women while in the urban only analyses the sample size was $n=23$ African countries.

The WHO surveys include surveys from UNICEF, UN Statistics Division, FAO, the World Bank, International Food Policy Research Institute (IFPRI) and the Demographic and Health Surveys (DHS) among others [14]. We used the WHO nutrition databases in this analysis because of the compiled, large number of different surveys included in addition to analyzing the DHS surveys, which present the opportunity for analyses of individual households.

\section{Demographic Health Surveys (DHS)}

Analysis was conducted also using the Demographic Health Surveys (DHS) for the following 26 sub-Saharan African countries specific years: Benin (2001), Burkina Faso (2003), Cameroon (2004), Congo (Brazzaville) 2005, Gabon (2000), Ghana (2003, 2008), Guinea (2003), Kenya (2003, 2008), Lesotho (2004, 2009), Liberia (2007), Madagascar (2003), Malawi (2000), Mali (2001, 2006), Mozambique (2003), Namibia (2007), Niger (2008), Nigeria (2003, 2008), Rwanda (2000), Sao Tome (2009), Senegal (2005), Sierra Leone (2006), Swaziland (2006), Tanzania (2005, 2010), Uganda (2006), Zambia (2002, 2007), Zimbabwe (2005). Countries were not included if they did not have a survey conducted in 2000 or later or if they did not include a measurement of maternal BMI and child anthropometrics as part of the information collected.

The children's file which included mother's BMI measurement and child anthropometrics was used for all analyses. Sampling weights were used in calculations as provided by the DHS [15]. In the DHS surveys, it was possible to evaluate individual households and the prevalence of double burden households. Similar to the WHO datasets, the age of the children in the DHS surveys is under 5 years. Using the DHS data, we evaluated the prevalence of double burden households by country surveyed as well as assessed whether this was higher in urban areas in comparison with rural areas or among mothers with a secondary education in comparison to those with no education or only a primary education. Maternal obesity was defined as having a BMI $\geq 30 \mathrm{~m} / \mathrm{kg}^{2}$, overweight (BMI $\geq 25 \mathrm{~m} / \mathrm{kg}^{2}$ ), underweight (BMI $<18.5 \mathrm{~m} / \mathrm{kg}^{2}$ ) and child stunting (having a height-for-age $\mathrm{Z}$ score $<-2$ standard deviations (SD) below the international reference median), underweight (having a weight-for-age $\mathrm{Z}$ score $<-2 \mathrm{SD}$ ) and wasting 
(having a weight-for-height $\mathrm{Z}$ score $<-2 \mathrm{SD}$ ). Analyses of double burden household prevalences used the definitions of undernutrition (and did not restrict to severe undernutrition alone $<-3 \mathrm{SD}$ ) given the low prevalence of double burden households using the more expansive definition. All analyses were conducted using Stata 13.0 and with svy commands.

\section{Results}

\section{WHO datasets}

The mean prevalence of adult obesity in the WHO dataset was $7.5 \pm 6.0 \%$ while adult overweight was much higher at $21.8 \pm 10.2 \%$ and adult underweight was $13.4 \pm 7.0 \%$. Stunting (<-2SD) was $38.7 \pm 7.8 \%$ and severe stunting $(<-3 S D)$ was $19.0 \pm 5.7 \%$. Underweight $(<-2 S D)$ was $21.5 \pm$ $8.8 \%$ and severe underweight $(<-3 \mathrm{SD})$ was $7.96 \pm 4.3 \%$. Wasting (<-2SD) was $10.0 \pm 4.4 \%$ and severe wasting (<-3SD) was $4.0 \pm 2.2 \%$. In the urban surveys, the prevalence of adult obesity and overweight were higher (12.5 \pm $7.0 \%$ and $31.8 \pm 12.8 \%$ ), child undernutrition was generally lower $(30.4 \pm 8.4 \%$ for stunting $<-2$ SD and $13.3 \pm$ $5.2 \%$ for severe stunting $<-3 \mathrm{SD}, 15.5 \pm 7.0 \%$ for underweight $<-2 \mathrm{SD}$ and $5.2 \pm 2.8 \%$ for underweight $<-3 \mathrm{SD}$ and $12.0 \pm 5.0 \%$ for wasting $<-2 \mathrm{SD}$ and $3.4 \pm 1.8 \%$ for wasting <-3SD) and adult underweight (10.5\%) was also lower.

In both the overall combined analysis using data from men and women and the analysis of just women, we found that there were significant relationships between the prevalence of adult BMI category and \% of children underweight, wasted, stunted, overweight or obese (Tables 1, 2, 3 and 4).

Specifically, looking at the associations in adult men and women, wasting (<-3SD) was positively associated with adult underweight, while wasting $(<-2 S \mathrm{~S})$ was positively associated with adult underweight and negatively associated with adult overweight and obesity (Table 1). For stunting, adult overweight and obesity were inversely associated with stunting while the association between adult underweight and severe stunting had a $\mathrm{p}$ value equal to 0.07 (Table 1). Child underweight (both $<-2 S D$ and $<-3 S D$ weight for age $\mathrm{Z}$ scores) was negatively associated with adult obesity and overweight and positively correlated with adult underweight. Child BMI Z score $<-2 \mathrm{SD}$ or $<-3 \mathrm{SD}$ (child wasting) was positively associated with adult underweight and child overweight and obesity were positively associated with adult overweight and obesity and negatively associated with adult underweight (Table 1).

In the restricted analyses, adult women only, the results were comparable to those that included men and women (Table 2). Using a smaller dataset from only urban surveys ( $n=23$ African countries), we found fewer associations. Child stunting was associated with adult underweight, as
Table 1 Association between prevalence of adult (men and women) weight parameters with child undernutrition and overweight/obesity: regressions using WHO survey data

\begin{tabular}{|c|c|c|c|}
\hline & $\begin{array}{l}\text { Adult } \\
\text { Obesity } \\
\beta \text { Coeff (SE) } \\
P \text { value }\end{array}$ & $\begin{array}{l}\text { Adult } \\
\text { Overweight } \\
\beta \text { Coeff (SE) } \\
\text { P value }\end{array}$ & $\begin{array}{l}\text { Adult } \\
\text { Underweight } \\
\beta \text { Coeff (SE) } \\
P \text { value }\end{array}$ \\
\hline \multicolumn{4}{|c|}{ Child Anthropometrics } \\
\hline Weight-Height & $-.30(.13)$ & $-.18(.08)$ & $.44(.09)$ \\
\hline Z Score $<-2$ SD & .03 & .03 & $<.01$ \\
\hline \multicolumn{4}{|l|}{ (Wasting) } \\
\hline Weight-Height & $-.12(.06)$ & $-.07(.04)$ & $.16(.05)$ \\
\hline$Z$ score $<-3 S D$ & .07 & .08 & $<.01$ \\
\hline \multicolumn{4}{|l|}{ (Severe wasting) } \\
\hline Height Z score & $-.70(.21)$ & $-.33(.09)$ & $.28(.15)$ \\
\hline$<-2 \mathrm{SD}$ & $<.01$ & $<.01$ & .07 \\
\hline \multicolumn{4}{|l|}{ (Stunting) } \\
\hline Height Z score & $-.51(.15)$ & $-.33(.08)$ & $.28(.15)$ \\
\hline$<-3 \mathrm{SD}$ & $<.01$ & $<.01$ & .07 \\
\hline \multicolumn{4}{|l|}{ (Severe stunting) } \\
\hline Weight Z score & $-.82(.24)$ & $-.56(.13)$ & $.96(.16)$ \\
\hline$<-2 S D$ & $<.01$ & $<.01$ & $<.01$ \\
\hline \multicolumn{4}{|l|}{ (Underweight) } \\
\hline Weight Z score & $-.37(.12)$ & $-.25(.07)$ & $.45(.08)$ \\
\hline$<-3 \mathrm{SD}$ & $<.01$ & $<.01$ & $<.01$ \\
\hline \multicolumn{4}{|c|}{ (Severe underweight) } \\
\hline BMI Z score & $-.26(.14)$ & $-.16(.06)$ & $.40(.10)$ \\
\hline$<-2$ SD & .07 & .06 & $<.01$ \\
\hline \multicolumn{4}{|l|}{ (Wasting) } \\
\hline BMI Z score & $-.11(.07)$ & $-.07(.04)$ & $.15(.06)$ \\
\hline$<-3 \mathrm{SD}$ & .13 & .14 & .02 \\
\hline \multicolumn{4}{|l|}{ (Severe wasting) } \\
\hline BMI Z score & $.31(.11)$ & $.18(.07)$ & $-.33(.09)$ \\
\hline$\geq+2 \mathrm{SD}$ & .01 & .02 & $<.01$ \\
\hline \multicolumn{4}{|c|}{ (Overweight and obese) } \\
\hline BMI Z score & $.10(.05)$ & $.06(.03)$ & $-.09(.04)$ \\
\hline$\geq+3 S D$ & .056 & .02 & .02 \\
\hline Obese & & & \\
\hline
\end{tabular}

was child underweight. Child overweight was inversely associated with adult underweight (Table 3). Using the urban sample with only women, the sole association that was significant was the inverse association between child overweight/obesity and adult underweight (Table 4).

The associations between adult obesity and underweight, and child severe stunting and severe underweight, are also 
Table 2 Association between prevalence of female adult weight parameters with child undernutrition and overweight/obesity frequencies: results from regressions using WHO data

\begin{tabular}{|c|c|c|c|}
\hline & $\begin{array}{l}\text { Adult } \\
\text { Obesity } \\
\beta \text { Coeff (SE) } \\
P \text { value }\end{array}$ & $\begin{array}{l}\text { Adult } \\
\text { Overweight } \\
\beta \text { Coeff (SE) } \\
P \text { value }\end{array}$ & $\begin{array}{l}\text { Adult } \\
\text { Underweight } \\
\beta \text { Coeff (SE) } \\
P \text { value }\end{array}$ \\
\hline \multicolumn{4}{|c|}{ Child Anthropometrics } \\
\hline Weight-Height & $-.29(.14)$ & $-.18(.07)$ & $.44(.09)$ \\
\hline$Z$ score $<-2$ SD & .04 & .01 & $<.01$ \\
\hline \multicolumn{4}{|l|}{ (Wasting) } \\
\hline Weight-Height & $-.12(.067)$ & $-.07(.03)$ & $.16(.05)$ \\
\hline$Z$ score $<-3$ SD & .08 & .04 & $<.01$ \\
\hline \multicolumn{4}{|l|}{ (Severe wasting) } \\
\hline Height Z Score & $-.74(.22)$ & $-.40(.11)$ & $.37(.20)$ \\
\hline$<-2 \mathrm{SD}$ & $<.01$ & $<.01$ & .08 \\
\hline \multicolumn{4}{|l|}{ (Stunting) } \\
\hline Height Z score & $-.53(.16)$ & $-.29(.08)$ & $.29(.14)$ \\
\hline$<-3 \mathrm{SD}$ & $<.01$ & $<.01$ & .06 \\
\hline \multicolumn{4}{|l|}{ (Severe stunting) } \\
\hline Weight Z Score & $-.83(.24)$ & $-.50(.11)$ & $.96(.15)$ \\
\hline$<-2 \mathrm{SD}$ & $<.01$ & $<.01$ & $<.01$ \\
\hline \multicolumn{4}{|l|}{ (Underweight) } \\
\hline Weight Z score & $-.37(.12)$ & $-.22(.06)$ & $.44(.08)$ \\
\hline$<-3 \mathrm{SD}$ & $<.01$ & $<.01$ & $<.01$ \\
\hline \multicolumn{4}{|c|}{ (Severe underweight) } \\
\hline BMI Z score & $-.25(.14)$ & $-.16(.07)$ & $.40(.09)$ \\
\hline$<-2 \mathrm{SD}$ & .08 & .03 & $<.01$ \\
\hline \multicolumn{4}{|l|}{ (Wasting) } \\
\hline BMI Z score & $-.11(.08)$ & $-.07(.04)$ & $.15(.06)$ \\
\hline$<-3 \mathrm{SD}$ & .14 & .09 & .02 \\
\hline \multicolumn{4}{|l|}{ (Severe wasting) } \\
\hline BMI Z score & $.29(.12)$ & $.17(.06)$ & $-.34(.08)$ \\
\hline$\geq+2 S D$ & .02 & $<0.01$ & $<.01$ \\
\hline \multicolumn{4}{|c|}{ (Overweight and obese) } \\
\hline BMI Z score & $.09(.05)$ & $.06(.02)$ & $-.10(.04)$ \\
\hline$\geq+3 S D$ & .06 & .02 & .01 \\
\hline (Obese) & & & \\
\hline
\end{tabular}

shown graphically in Figures 1, 2 and 3. In Figure 1, the reduced prevalence of childhood stunting is shown in countries that have an increased prevalence of adult obesity while adult underweight is associated with a higher prevalence of child underweight by country (Figure 2). Increased childhood stunting by country is also modestly associated with increased prevalence of adult underweight (Figure 3).
Table 3 Association between prevalence of urban adult weight parameters with child malnutrition and overweight/obesity frequencies: results from regressions using WHO survey data

\begin{tabular}{|c|c|c|c|}
\hline & $\begin{array}{l}\text { Adult } \\
\text { Obesity } \\
\beta \text { Coeff (SE) } \\
\text { P value }\end{array}$ & $\begin{array}{l}\text { Adult } \\
\text { Overweight } \\
\beta \text { Coeff (SE) } \\
P \text { value }\end{array}$ & $\begin{array}{l}\text { Adult } \\
\text { Underweight } \\
\beta \text { Coeff (SE) } \\
P \text { value }\end{array}$ \\
\hline \multicolumn{4}{|c|}{ Child Anthropometrics } \\
\hline Weight-Height & $-.10(.14)$ & $-.03(.07)$ & $.18(.13)$ \\
\hline Z score $<-2$ SD & .47 & .66 & .18 \\
\hline \multicolumn{4}{|l|}{ (Wasting) } \\
\hline Weight-Height & $-.03(.07)$ & $-.01(.04)$ & $.04(.07)$ \\
\hline Z Score $<-3 S D$ & .68 & .85 & .58 \\
\hline \multicolumn{4}{|l|}{ (Severe wasting) } \\
\hline Height Z score & $-.30(.25)$ & $-16(.13)$ & $.54(.23)$ \\
\hline$<-2$ SD & .24 & .25 & .03 \\
\hline \multicolumn{4}{|l|}{ (Stunting) } \\
\hline Height Z score & $-.09(.17)$ & $-.07(.08)$ & $.29(.15)$ \\
\hline$<-3$ SD & .58 & .46 & .08 \\
\hline \multicolumn{4}{|l|}{ (Severe stunting) } \\
\hline Weight Z score & $-.34(.24)$ & $-.14(.13)$ & $.66(.20)$ \\
\hline$<-2 S D$ & .19 & .31 & $<.01$ \\
\hline \multicolumn{4}{|l|}{ (Underweight) } \\
\hline Weight Z score & $-.08(.10)$ & $-.03(.05)$ & $.16(.09)$ \\
\hline$<-3 S D$ & .43 & .64 & .10 \\
\hline \multicolumn{4}{|c|}{ (Severe underweight) } \\
\hline BMI Z score & $-.07(.14)$ & $-.02(.07)$ & $.13(.14)$ \\
\hline$<-2 \mathrm{SD}$ & .63 & .81 & .33 \\
\hline \multicolumn{4}{|l|}{ (Wasting) } \\
\hline BMI Z score & $-.01(.07)$ & $-.003(.04)$ & $.02(.07)$ \\
\hline$<-3 \mathrm{SD}$ & .89 & .94 & .75 \\
\hline \multicolumn{4}{|l|}{ (Severe wasting) } \\
\hline BMI Z score & $14(.14)$ & $.019(.07)$ & $-.29(.11)$ \\
\hline$\geq 2 \mathrm{SD}$ & .32 & .81 & .02 \\
\hline \multicolumn{4}{|c|}{ (Overweight and obese) } \\
\hline BMI Z score & $.04(.04)$ & $.004(.02)$ & $-.06(.04)$ \\
\hline$\geq 3 \mathrm{SD}$ & .36 & .87 & .13 \\
\hline (Obese) & & & \\
\hline
\end{tabular}

\section{DHS data}

The overall prevalence of maternal overweight and obesity in the 27 DHS countries surveyed was $16.5 \%$ (95\% CI 16.1-17.0\%), maternal obesity was 5.1\% (95\% CI 4.8-5.3\%) and maternal underweight was $10.4 \%$ (95\% CI 10.1$10.7 \%)$. The prevalence of maternal overweight and obesity was higher than $20 \%$ in the following countries and years: Congo 2005, Ghana 2008, Namibia 2007, Nigeria 
Table 4 Association between prevalence of urban female adult weight parameters with child undernutrition and overweight/obesity frequencies: results from regressions using WHO survey data

\begin{tabular}{|c|c|c|c|}
\hline & $\begin{array}{l}\text { Adult } \\
\text { Obesity } \\
\beta \text { Coeff (SE) } \\
P \text { value }\end{array}$ & $\begin{array}{l}\text { Adult } \\
\text { Overweight } \\
\beta \text { Coeff (SE) } \\
P \text { value }\end{array}$ & $\begin{array}{l}\text { Adult } \\
\text { Underweight } \\
\beta \text { Coeff (SE) } \\
P \text { value }\end{array}$ \\
\hline \multicolumn{4}{|c|}{ Child Anthropometrics } \\
\hline Weight-Height & $-.08(.11)$ & $-.04(.06)$ & $.19(.13)$ \\
\hline$Z$ score $<-2$ SD & .46 & .54 & .14 \\
\hline \multicolumn{4}{|l|}{ (Wasting) } \\
\hline Weight-Height & $-.03(.05)$ & $-.01(.03)$ & $.05(.06)$ \\
\hline Z score $<-3 S D$ & .54 & .64 & .47 \\
\hline \multicolumn{4}{|l|}{ (Severe wasting) } \\
\hline Height Z score & $-.19(.20)$ & $-.14(.12)$ & $.47(.23)$ \\
\hline$<-2 \mathrm{SD}$ & .36 & .24 & .052 \\
\hline \multicolumn{4}{|l|}{ (Stunting) } \\
\hline Height Z score & $-.05(.13)$ & $-.06(.08)$ & $.26(.15)$ \\
\hline$<-3 \mathrm{SD}$ & .70 & .43 & .11 \\
\hline \multicolumn{4}{|l|}{ (Severe stunting) } \\
\hline Weight Z Score & $-.08(.11)$ & $-.04(.06)$ & $.19(.13)$ \\
\hline$<-2 S D$ & .46 & .54 & .14 \\
\hline \multicolumn{4}{|l|}{ (Underweight) } \\
\hline Weight Z score & $-.03(.05)$ & $-.015(.03)$ & $.05(.06)$ \\
\hline$<-3 \mathrm{SD}$ & .54 & .64 & .47 \\
\hline \multicolumn{4}{|c|}{ (Severe underweight) } \\
\hline BMI Z score & $-.05(.11)$ & $-.03(.06)$ & $.14(.13)$ \\
\hline$<-2 \mathrm{SD}$ & .64 & .70 & .28 \\
\hline \multicolumn{4}{|l|}{ (Wasting) } \\
\hline BMI Z score & $-.02(.06)$ & $-.01(.03)$ & $.03(.07)$ \\
\hline$<-3 \mathrm{SD}$ & .77 & .77 & .62 \\
\hline \multicolumn{4}{|l|}{ (Severe wasting) } \\
\hline BMI Z score & $.09(.11)$ & $.03(.06)$ & $-.26(.11)$ \\
\hline$\geq 2 \mathrm{SD}$ & .44 & .78 & .03 \\
\hline \multicolumn{4}{|c|}{ (Overweight and obese) } \\
\hline BMI Z score & $.02(.03)$ & $.004(.02)$ & $-.06(.04)$ \\
\hline$\geq 3 \mathrm{SD}$ & .50 & .83 & .15 \\
\hline (Obese) & & & \\
\hline
\end{tabular}

2003, Nigeria 2008, Sao Tome 2009, Sierra Leone 2006, Swaziland 2006 and Zimbabwe 2005 (Figure 4). The overall prevalence was higher in urban areas for maternal overweight and obesity (30.3\% (95\% CI 29.5-31.2\%) and obesity $10.5 \%$ (95\% CI 10.0-11.0\%)) but lower for maternal underweight $(7.6 \%, 95 \%$ CI 7.1-8.0\%) in comparison with the national prevalence. The overall prevalence of child stunting (<-2SD) was $37.8 \%$, (95\% CI 37.4-38.3\%) and severe stunting (<-3SD) was $17.4 \%$ (95\% CI 17.1-17.8\%), wasting (<-2SD) was $8.4 \%$ (<-3SD was $1.8 \%$ (95\% CI 1.75$1.94 \%)$ and underweight (<-2SD) was $25.5 \%,(95 \% \mathrm{CI}$, 25.1-26.0\%) and severe underweight (<-3SD) 7.3\% (95\% CI 7.1-7.5\%). The child undernutrition prevalence was lower in the urban areas $(27.2 \%$ (95\% CI 26.5-28.0\%) for stunting, 7.1\% (95\% CI 6.7-7.5\%) for wasting and $17.4 \%$ (95\% CI 16.8-18.1\%) for underweight) in comparison with national prevalence. There was no observable association at the country level between maternal overweight and obesity and child undernutrition although the percentage of maternal overweight and obesity appeared to decrease with higher levels of child undernutriiton (Figures 5, 6 and 7).

The prevalence of households that included an obese mother with a child with undernutrition (defined as stunted, underweight or wasted) was less than $5 \%$ for all the countries surveyed with the exception of Swaziland in 2006, which had a prevalence of $9.50 \%$ for the pairing of an obese mother with an underweight child (Table 5). The total prevalence of double burden houses combining all the households from the countries surveyed was $0.50 \%$ (95\% CI $0.46-0.55 \%$ ) for obese mother/underweight child pairs, $0.98 \%$ (95\% CI $0.91-1.06 \%$ ) for obese mother/stunted child and $0.24 \%$ (95\% CI $0.21-0.27 \%$ ) for obese mother/wasted child (Table 5).

When the double burden household analysis was restricted to urban households only, the prevalence of double burden households was not significantly increased. For obese mothers/underweight child pairs the prevalence was 0.92\% (95\% CI $0.81-1.04 \%$ ), $1.79 \%$ (95\% CI $1.62-1.98 \%$ ) for obese mothers/stunted child pairs and 0.50\% (95\% CI 0.42$0.59 \%$ ) for obese mothers/wasted child pairs (Table 5). Restricting the analysis to those who had completed some secondary education, the prevalence was similar at 0.93\% for obese mother/underweight child pairs, $1.46 \%$ for obese mother/stunted child pairs and $0.59 \%$ for obese mother/ wasted child pairs (Table 5). The prevalence of maternal overweight and child undernutrition was higher than that found for obese mothers: 4.34\% (95\% CI 4.19-4.50\%) for maternal overweight and child stunting, 2.11\% (95\% CI 2.02-2.22\%) for maternal overweight and child underweight and maternal overweight and child wasting was $0.89 \%$ (95\% CI $0.83-0.96 \%$ ). These prevalence were also higher when restricted to urban areas alone $(6.11 \%$ for overweight/stunted pairs, 3.19\% (95\% CI 2.96-3.43\%) for overweight/underweight pairs and $1.68 \%$ (95\% CI 1.53 $1.86 \%$ ) for overweight/wasted pairs).

The overall prevalence of underweight mothers with children with undernutrition was higher in the subSaharan African countries surveyed. The prevalence for underweight mother/underweight child pairs was $4.85 \%$ (95\% CI 4.67-5.04\%), 4.74\% (95\% CI 4.56-4.92\%) for underweight mother with stunted child, and 1.50\% (95\% CI 1.41-1.59\%) for underweight mother with wasted child 


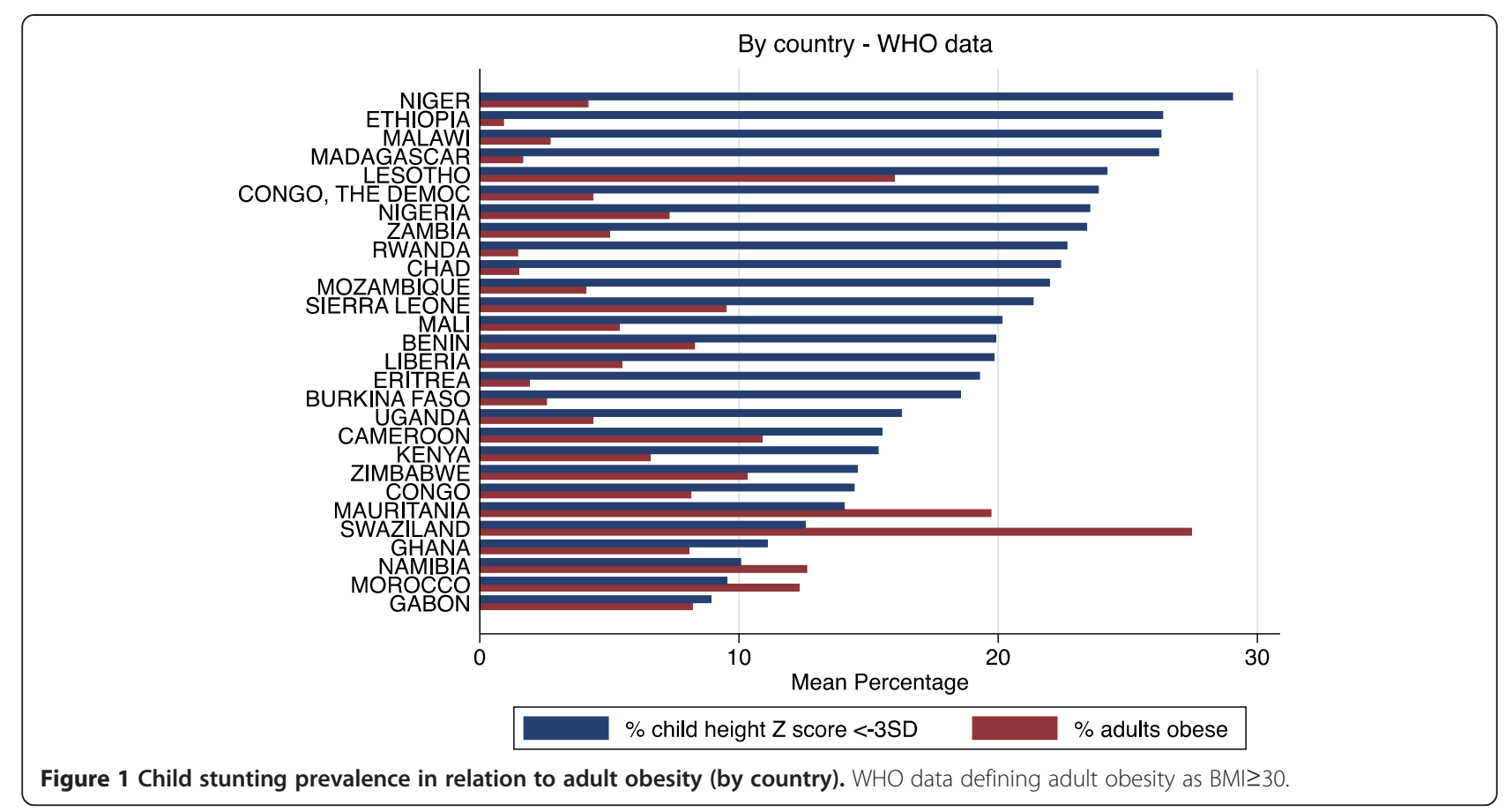

(Table 6). Meanwhile, the overall prevalence of maternal underweight was $10.4 \%$. However, the prevalence of an underweight mother with a child with undernutrition was greater than $5 \%$ for 8 countries and approached 10\% in some cases (Table 6). The prevalence of underweight moms with child undernutrition was noticeably lower when restricted to urban areas or those mothers with some secondary education (Table 6).

While prevalence for childhood stunting and underweight are high in all of the countries surveyed (between $30-40 \%$ for stunting and $20-30 \%$ for underweight for many of the countries), a clear trend in the association between childhood undernutrition and maternal obesity or overweight does not emerge.

\section{Discussion}

\section{Low prevalence of double burden households}

The overall prevalence of double burden households in the sub-Saharan African countries surveyed was not significantly higher than that found by the other studies, $[8,9]$ which evaluated the double burden prevalence using DHS and other surveys in the time period up until

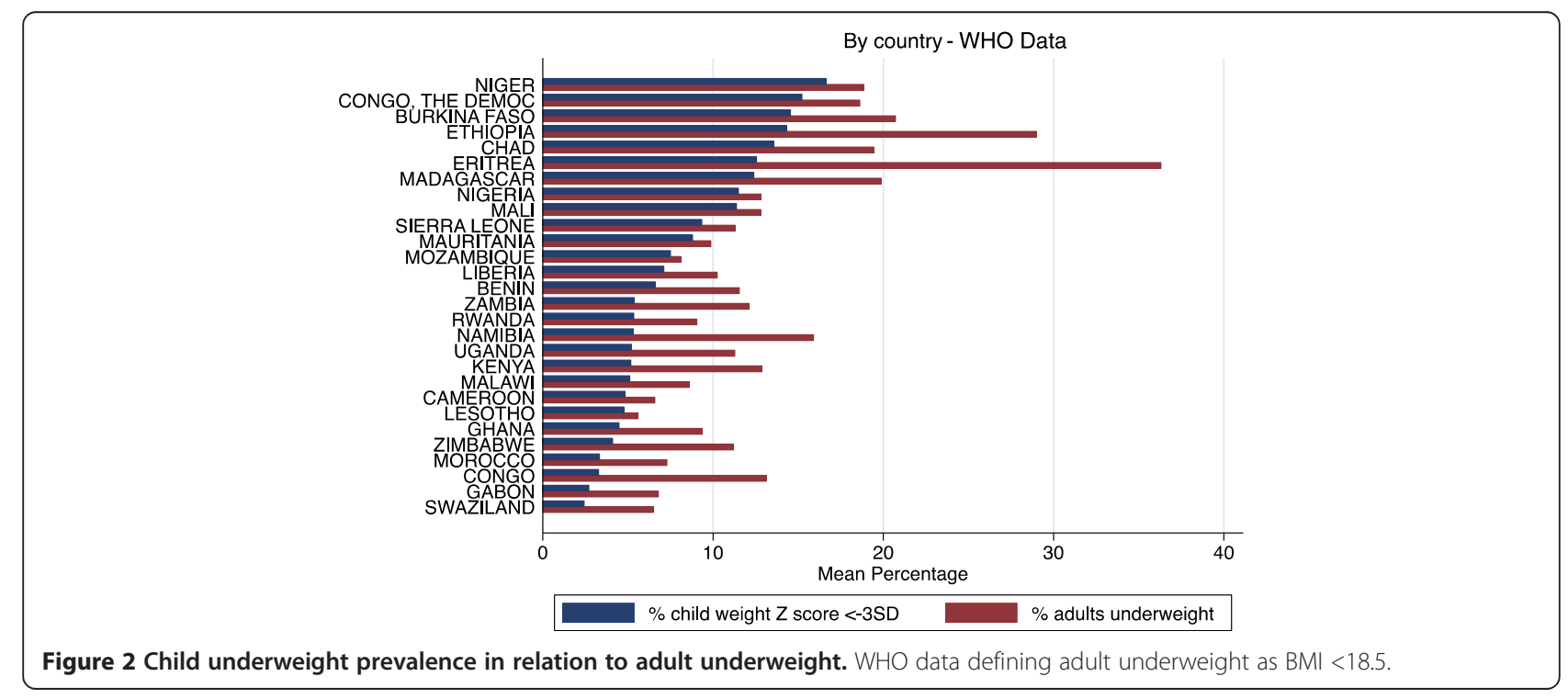




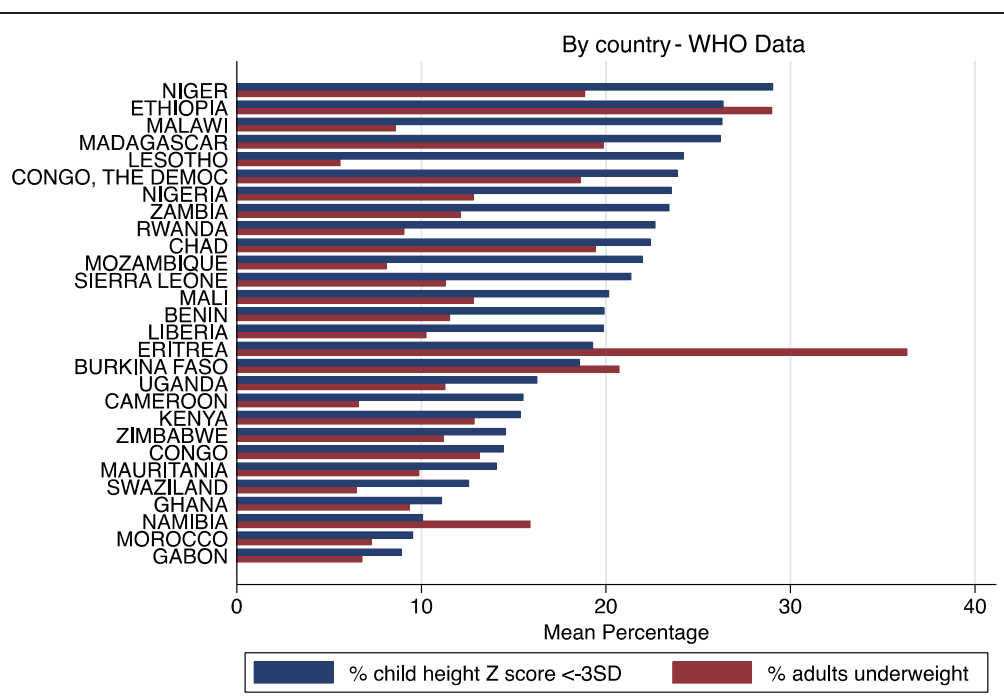

Figure 3 Child stunting prevalence in relation to adult underweight (by country). WHO data defining adult underweight as a BMI $<18.5$.

the early 2000s. A higher prevalence was observed for double burden households defined as maternal overweight with child undernutrition in comparison with maternal obesity and child undernutrition, however, the prevalence of these types of double burden households was still less than $10 \%$ and was not higher than $10 \%$ in any individual country or year. The prevalence of households with maternal underweight paired with child undernutrition was also less than $10 \%$ for any individual country or year, although the prevalence was higher than for the double burden households with maternal overweight or obesity.
When the analyses were restricted to urban areas or women with a higher educational background, the prevalence of double burden households did not change remarkably, although slightly higher for maternal obesity and child undernutrition households. This was not surprising as the overall percentage of undernutrition in children is lower in urban areas compared with national prevalences even though the prevalence of obese and overweight women is higher. Other studies using African DHS data to evaluate trends over time have found that the prevalence of urban adult overweight and obesity

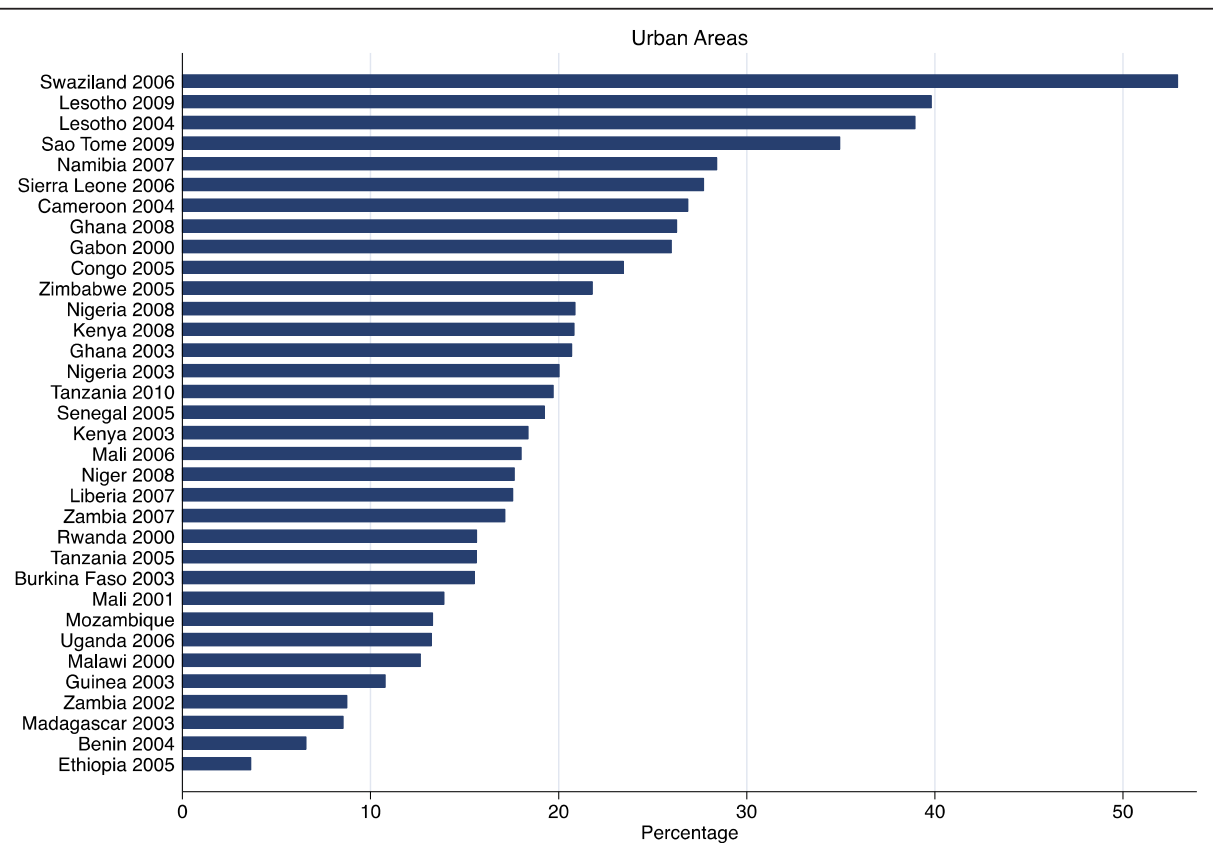

Figure 4 DHS maternal overweight and obesity by country. DHS data defining maternal overweight and obesity as BMI $\geq 25$. 


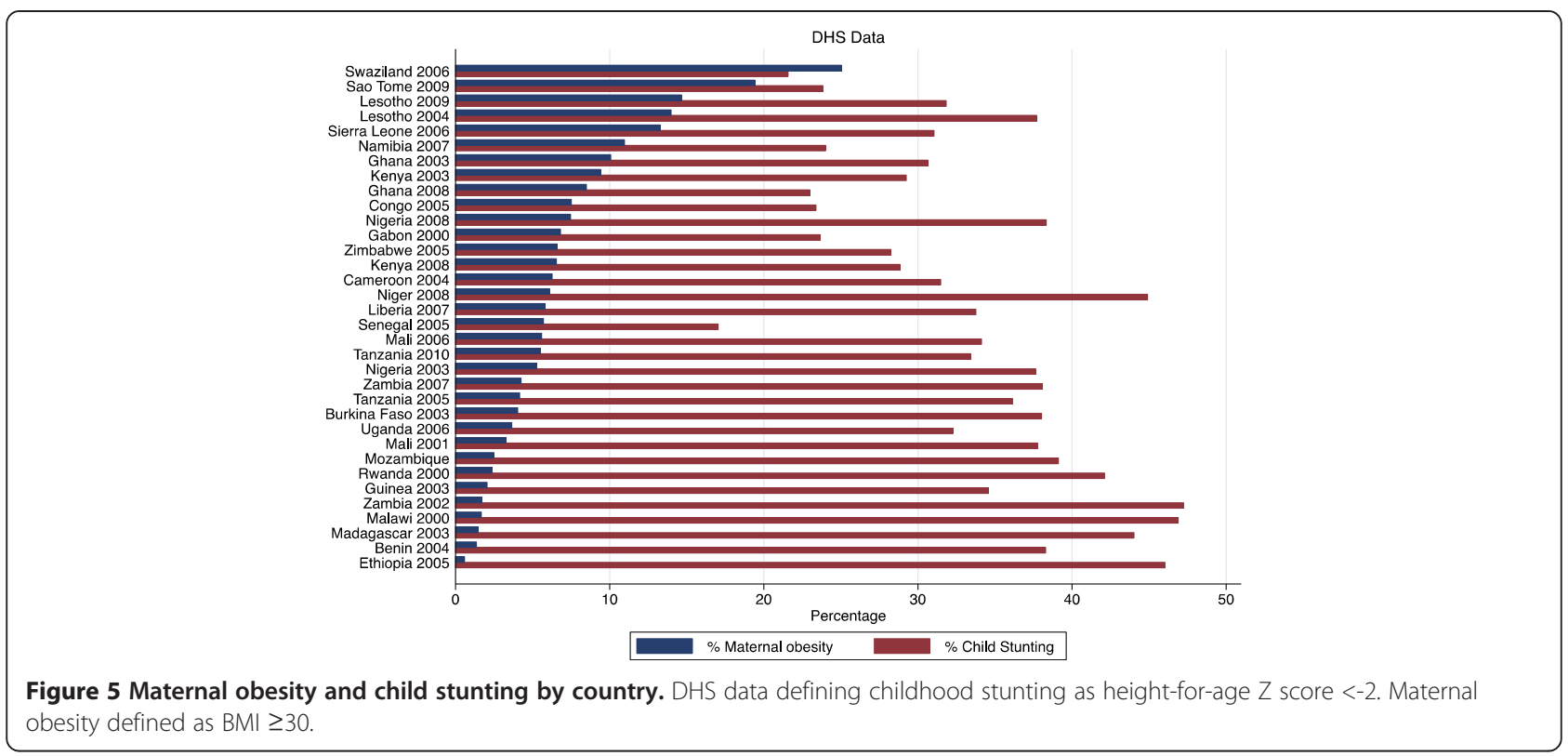

increased by 35\% from 1992 to 2005 approaching 30\% in urban areas [5]. Meanwhile, the prevalence of child undernutrition, specifically stunting, has not changed significantly in the last 10-20 years in African countries [16] and underweight has increased [17] although it is not clear if child undernutrition prevalence is lower in urban areas.

These findings are in contrast with some previous studies, which have found a higher prevalence of double burden households in sub-Saharan African countries and have predicted an increase in prevalence in coming years such as the study by Bouzitou et al. in 2005, [10] which found a prevalence of $16.2 \%$ of double burden households (combining households with childhood stunting $(<-2$ height-for- age $\mathrm{Z}$ score) and wasting ( $<-2$ weight-for-height $\mathrm{Z}$ score) and overweight mothers in urban Cotonou (Benin). However, in the study by Jehn and Brewis published in 2009 [8], only Ghana had a prevalence of overweight motherstunted child pairs $>10 \%$ out of 9 African countries surveyed. Similarly, the review by Garrett and Ruel [9] of 23 North African and sub-Saharan African countries using earlier DHS surveys found less than $10 \%$ of households had an overweight mother and stunted child (with the exception of Egypt). Our study, however, was more comprehensive than the study by Garrett and Ruel [9] and the one by Jehn and Brewis [8], which did not include the most recent DHS surveys.

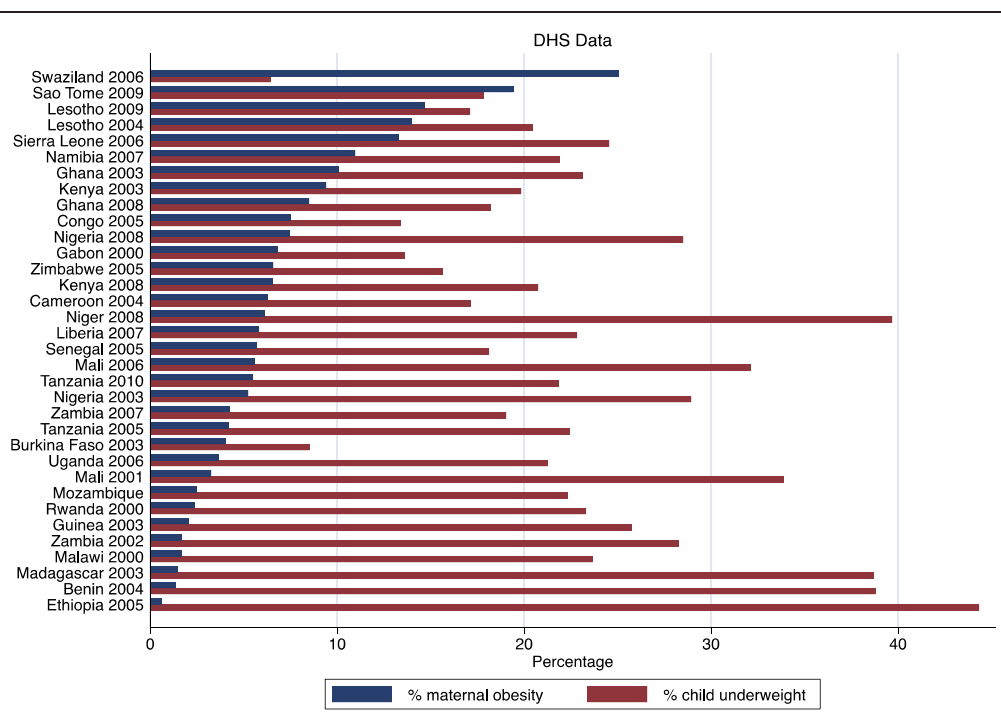

Figure 6 Maternal obesity and child underweight by country. DHS data defining childhood underweight as weight-for-age Z score $<-2$ Maternal obesity defined as $\mathrm{BMI} \geq 30$. 


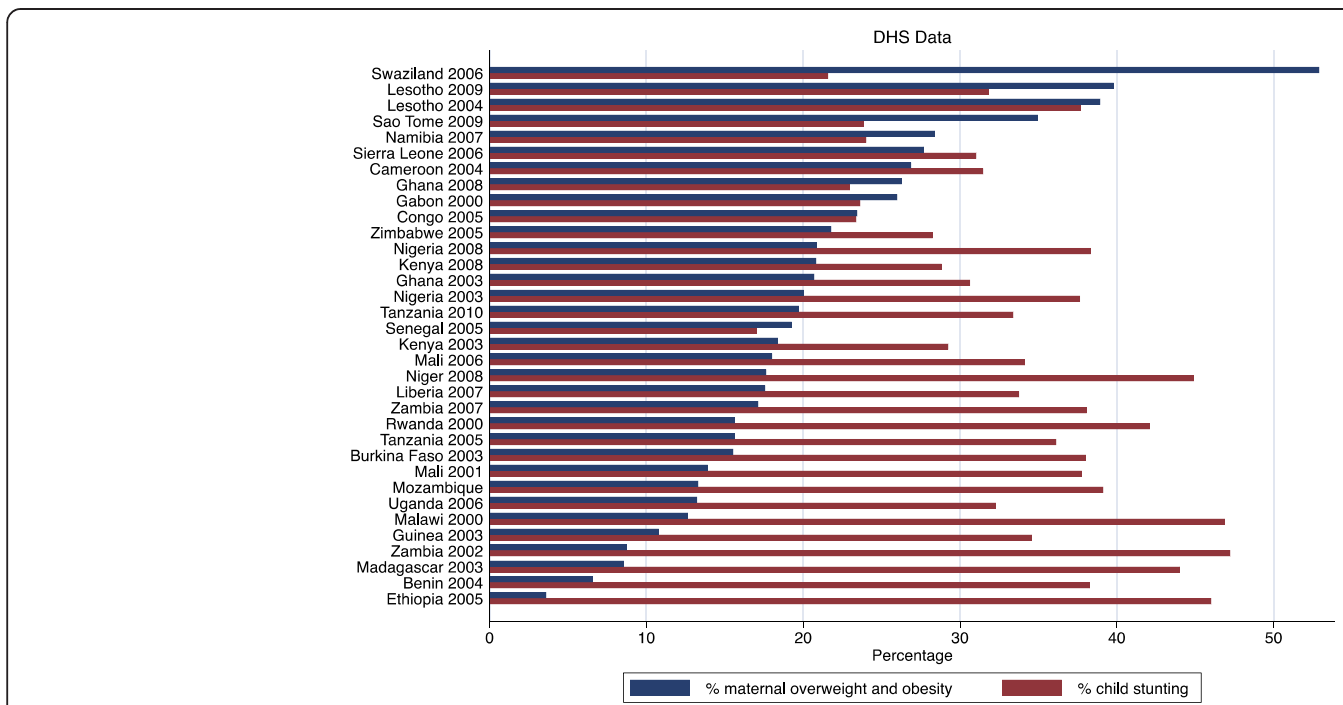

Figure 7 Maternal overweight and obesity in relation to child stunting by country. DHS data defining childhood stunting as height-for-age $Z$ score $<-2$. Maternal overweight and obesity defined as BMI $\geq 25$.

\section{Increases in maternal overweight/obesity}

Jehn and Brewis [8] conclude that any possible increases in the existence of double burden households should be attributed to the overall increase in the prevalence of overweight and obesity in women in developing countries, rather than any observable increase in child undernutrition in relation to adult overweight/obesity. As we did not investigate changes in prevalence of child undernutritition or adult obesity in any of the sub-Saharan African countries surveyed, it is outside of the scope of this paper to speculate on trends in prevalence of adult obesity or child undernutrition. However, we did not find any increase in the prevalence of double burden household relative to the earlier study done by Jehn and Brewis [8] also using DHS data.

We also found a high prevalence of overweight and obesity in women in all the sub-Saharan African countries surveyed, particularly in urban areas, in excess of $30 \%$ in many sub-Saharan African countries and exceeding $40 \%$ in a few (Figure 4). Moreover, this trend is particularly evident among women who have completed more education (secondary education), with all but 6 of the 26 countries included in the analysis, having greater than $40 \%$ overweight and obesity for educated women. As the prevalence of underweight, stunting and wasting were all lower in urban areas, those areas that correspondingly had the highest levels of overweight and obesity, it is possible the low percentage of double burden households reflects the low prevalence of undernutrition, irrespective of the concomitant increases in overweight/ obesity. Alternatively, Garrett and Ruel [9] also found a low prevalence of double burden households (stunted children and overweight mothers) in African urban areas but had a different explanation. They concluded that higher levels of economic development and urbanization (than currently present in African urban areas) would increase adult obesity but not necessarily ameliorate the prevalence of child underweight, which would still be at significant levels, resulting in an increase in double burden households. Many sub-Saharan African countries may not meet this threshold for economic development.

In the regression analyses using WHO datasets which included more surveys than the DHS analysis, there was a negative association between overweight/obesity in women and child undernutrition and a positive association between underweight in women and child undernutrition as expected. We did not see any negative relationship between overweight/obesity in women and child undernutrition when restricting the analysis to urban areas only. It is possible that because of the relatively high overall prevalence of adult overweight/obesity irrespective of household category, particularly in the urban only surveys, greater power is needed to assess any statistical association between overweight/ obese mothers and children with undernutrition.

In the WHO and DHS analyses, there was no adjustment or stratification based on household income levels. Previous studies have found that the highest income households, particularly in urban areas were the most likely to be double burden households with the study by Doak et al. [7] reporting these findings from Vietnam, China, Indonesia, Brazil and the United States (2005). Doak et al. [7], also note that the lowest prevalence of double burden households are in those countries that have the lowest prevalence of overweight and obesity, such a Vietnam, and are at an earlier stages of the nutrition transition. However, in contrast with the study conducted by Doak et al. [7], the prevalence of overweight and obesity was high in the urban African women from 
Table 5 Frequency of maternal obesity and child undernutrition by country in DHS surveys

\begin{tabular}{|c|c|c|c|}
\hline & $\begin{array}{l}\text { Obese mom/ } \\
\text { child UW }\end{array}$ & $\begin{array}{l}\text { Obese mother/ } \\
\text { stunted child }\end{array}$ & $\begin{array}{l}\text { Obese mother/ } \\
\text { wasted child } \\
\text { Percentage (\%) }\end{array}$ \\
\hline & Percentage (\%) & & Percentage (\%) \\
\hline Benin 2004 & 0.18 & 1.64 & .00 \\
\hline Burkina Faso 2003 & 0.00 & 0.84 & .20 \\
\hline Cameroon 2004 & - & - & - \\
\hline Congo 2005 & 0.42 & 1.51 & 0.33 \\
\hline Gabon 2000 & 0.47 & 1.18 & 0.18 \\
\hline Ghana 2003 & 2.75 & 2.88 & 0.51 \\
\hline Ghana 2008 & 0.58 & 0.74 & 0.31 \\
\hline Guinea 2003 & 0.38 & 0.25 & 0.37 \\
\hline Kenya 2003 & 1.15 & 1.67 & 0.32 \\
\hline Kenya 2008 & - & - & - \\
\hline Lesotho 2004 & 2.12 & 4.86 & 0.68 \\
\hline Lesotho 2009 & 1.66 & 4.35 & 0.28 \\
\hline Liberia 2007 & 0.83 & 1.31 & 0.17 \\
\hline Madagascar 2003 & 0.10 & 0.13 & 0.00 \\
\hline Malawi 2000 & 0.17 & 0.52 & 0.00 \\
\hline Mali 2001 & 0.40 & 0.48 & 0.15 \\
\hline Mali 2006 & 0.88 & 1.01 & 0.51 \\
\hline Mozambique 2003 & 0.16 & 0.35 & 0.00 \\
\hline Namibia 2007 & 1.35 & 1.89 & 0.51 \\
\hline Niger 2008 & 0.37 & 0.54 & 0.11 \\
\hline Nigeria 2003 & 0.73 & 1.51 & 0.59 \\
\hline Nigeria 2008 & 1.08 & 1.81 & 0.63 \\
\hline Rwanda 2000 & 0.24 & 0.49 & 0.00 \\
\hline Sao Tome 2009 & 2.38 & 4.29 & 1.31 \\
\hline Senegal 2005 & 0.51 & 0.69 & 0.30 \\
\hline Sierra Leone 2006 & 2.22 & 2.89 & 1.00 \\
\hline Swaziland 2006 & 9.50 & 4.47 & 4.30 \\
\hline Tanzania 2005 & 2.90 & 0.66 & 0.11 \\
\hline Tanzania 2010 & 4.90 & 0.81 & 0.00 \\
\hline Uganda 2006 & 0.44 & 0.69 & 0.10 \\
\hline Zambia 2002 & 0.23 & 0.57 & 0.00 \\
\hline Zambia 2007 & 0.34 & 0.94 & 0.00 \\
\hline Zimbabwe 2005 & 0.46 & 1.37 & 0.23 \\
\hline $\begin{array}{l}\text { Mean all } \\
\text { countries: }\end{array}$ & 0.50 & 0.98 & 0.24 \\
\hline Mean urban: & 0.92 & 1.79 & 0.50 \\
\hline $\begin{array}{l}\text { Mean some } \\
\text { secondary }\end{array}$ & 0.93 & 1.46 & 0.59 \\
\hline Education: & & & \\
\hline
\end{tabular}

Maternal obesity defined as having a $B M I \geq 30 \mathrm{~m} / \mathrm{kg}^{2}$. Child stunting was defined as having a height-for-age $Z$ score $<-2$ SD, underweight (UW) was having a weight-for-age $Z$ score $<-2$ SD and wasting was having a weight-for-height $Z$ score $<-2 S D$.
Table 6 Frequency of maternal underweight (UW) and child undernutrition by country in DHS surveys

\begin{tabular}{|c|c|c|c|}
\hline & $\begin{array}{l}\text { UW mother/ } \\
\text { UW child }\end{array}$ & $\begin{array}{l}\text { UW mother/ } \\
\text { stunted child }\end{array}$ & $\begin{array}{l}\text { UW mother/ } \\
\text { wasted child }\end{array}$ \\
\hline & Percentage (\%) & & \\
\hline Benin 2004 & 8.80 & 7.41 & 4.99 \\
\hline Burkina Faso 2003 & 8.26 & 3.97 & 0.72 \\
\hline Cameroon 2004 & - & - & - \\
\hline Congo 2005 & 0.42 & 2.92 & 1.27 \\
\hline Gabon 2000 & 1.52 & 1.69 & 0.37 \\
\hline Ghana 2003 & 2.75 & 2.88 & 1.08 \\
\hline Ghana 2008 & 1.94 & 1.93 & 1.14 \\
\hline Guinea 2003 & 4.31 & 4.59 & 1.88 \\
\hline Kenya 2003 & 4.29 & 4.61 & 1.52 \\
\hline Kenya 2008 & - & - & - \\
\hline Lesotho 2004 & 1.43 & 1.71 & 0.17 \\
\hline Lesotho 2009 & 1.07 & 1.71 & 0.17 \\
\hline Liberia 2007 & 2.68 & 3.30 & 6.50 \\
\hline Madagascar 2003 & 9.91 & 9.79 & 3.12 \\
\hline Malawi 2000 & 2.17 & 2.84 & 0.43 \\
\hline Mali 2001 & 4.05 & 3.86 & 1.61 \\
\hline Mali 2006 & 4.77 & 4.08 & 1.97 \\
\hline Mozambique 2003 & 2.98 & 3.83 & 0.74 \\
\hline Namibia 2007 & 4.64 & 4.35 & 1.78 \\
\hline Niger 2008 & 7.78 & 7.23 & 1.99 \\
\hline Nigeria 2003 & 5.41 & 6.32 & 1.59 \\
\hline Nigeria 2008 & 4.97 & 5.59 & 2.01 \\
\hline Rwanda 2000 & 1.80 & 2.2 & 0.49 \\
\hline Sao Tome 2009 & 1.18 & 4.29 & 0.42 \\
\hline Senegal 2005 & 3.13 & 1.99 & 1.79 \\
\hline Sierra Leone 2006 & 3.77 & 3.99 & 1.64 \\
\hline Swaziland 2006 & 0.23 & 0.60 & 0.00 \\
\hline Tanzania 2005 & 2.57 & 2.85 & 0.55 \\
\hline Tanzania 2010 & 3.25 & 3.25 & 0.72 \\
\hline Uganda 2006 & 3.08 & 3.58 & 1.02 \\
\hline Zambia 2002 & 4.78 & 6.25 & 0.82 \\
\hline Zambia 2007 & 3.68 & 3.68 & 0.58 \\
\hline Zimbabwe 2005 & 2.12 & 2.70 & 0.79 \\
\hline $\begin{array}{l}\text { Mean all } \\
\text { countries: }\end{array}$ & 4.85 & 4.74 & 1.50 \\
\hline Mean urban: & 3.10 & 2.73 & 0.88 \\
\hline $\begin{array}{l}\text { Mean some } \\
\text { secondary }\end{array}$ & 0.45 & 0.64 & 0.22 \\
\hline Education: & & & \\
\hline
\end{tabular}

Maternal underweight defined as having a BMI $<18.5 \mathrm{~m} / \mathrm{kg}^{2}$. Child stunting was defined as having a height-for-age $Z$ score $<-2$ SD, underweight was having a weight-for-age $Z$ score $<-2$ SD and wasting was having a weight-for-height $Z$ score $<-2 S D$. 
the countries we surveyed while the prevalence of double burden households was low. We would have anticipated seeing a higher percentage of double burden households, and yet the overall prevalence of double burden households is much less than that reported for countries with lower levels of adult obesity such as Indonesia, Brazil and Krgyzstan (above 10\% for each).

As argued by Garrett and Ruel [9], it is possible that the level of economic development, irrespective of urbanization status, is not high enough in the African countries surveyed to account for a greater percentage of double burden households. During the nutrition transition, individual diets become more important rather than factors affecting the entire household such as food security or income. Additionally, the increasing availability of cheaper, energydense, low quality, nutrient poor foods could account for the concomitant existence of child undernutrition and adult overweight. It is possible that the availability of these food items is more limited in urban African areas in contrast with Latin American or Asian counterparts. Specifically, the consumption of soda/soft drinks is much higher in Latin America than African countries [18].

Future studies need to assess the dietary intake of double burden households in contrast with normal weight or underweight households. In the study by Bouzitou et al. [10] from Benin, those households that were at the greatest risk for being double burden were household that had the lowest food diversity scores, however, it is not clear how food diversity in the urban African context relates to income or consumption of energy dense, low nutrient value foods.

\section{Conclusions}

Further studies need to be conducted on the relation between household income and risk for double burden households in sub-Saharan African countries as well as to better characterize the nutrition transition in African countries. These studies should focus on explaining the seeming paradox of a low prevalence of double burden households in urban areas with increasing adult obesity rates. Furthermore, the increasing obesity prevalence and the failure to decrease child under-nutrition in African countries suggested by Ziraba et al. [5] and de Onis et al. [16] points to the possibility that double burden homes will be a growing problem. Interventions that target households as a whole to increase food availability and access, should be combined with approaches that encourage access to better quality food stuffs, to prevent the concurrent development of obesity.

\section{Competing interests}

The author declares that she has no competing interests.

\section{Authors' contributions}

JMW came up with the study idea, wrote the manuscript and conducted all analyses.

\section{Acknowledgements}

Funding was supported in part by NIH NIDDK 080825.

Received: 19 March 2013 Accepted: 16 October 2014

Published: 31 October 2014

\section{References}

1. WHO: Obesity and Overweight (Fact Sheet No. 311). Geneva: WHO; 2011

2. Black RE, Allen LH, Bhutta ZA, Caulfield LA, de Onis M, Ezzati M, Mathers C, Rivera J, for the Maternal Child Undernutrition Study Group: Maternal and child undernutrition: global and regional exposures and health outcomes. Lancet 2008, 371(9608):243-260.

3. UNICEF: Progress for Children: A World Fit for Children Statistical Review, Number 6. New York: New York: United Nation's Children Fund; 2007.

4. UNICEF: 2008 The State of the World's Children 2008: Child Survival. New York: New York: United Nations Children's Fund; 2007.

5. Ziraba AK, Fotso JC, Ochako R: Overweight and obesity in urban Africa: a problem of the rich or the poor? BMC Public Health 2009, 9:465.

6. De Onis M, Blossner M, Borghi E: Global prevalence and trends of overweight and obesity among preschool children. Am J Clin Nutr 2010, 92:1257-1264.

7. Doak CM, Adair LS, Bentley M, Monteiro C, Popkin BM: The dual burden household and the nutrition transition paradox. Int J Obes (Lond) 2005, 29(1):129-136

8. Jehn M, Brewis A: Paradoxical malnutrition and the phenomenon of over and undernutrition in underdeveloped economies. Econ Hum Biol 2009, 7:28-35

9. Garrett JL, Ruel MT: Stunted Child-Overweight Mother Pairs: An Emerging Policy Concern? Food Consumption and Nutrition Division Discussion Paper, No. 148. Washington DC: International Food Policy Research Institute; 2003.

10. Bouzitou DN, Fayomi B, Delisle H: Child malnutrition and maternal overweight in same households in poor urban areas of Benin. Sante 2005, 15(4):263-270.

11. World Health Organization (WHO): Global Database on Child Growth and Malnutrition. 2011. http://www.who.int/nutgrowthdb/database/en/, accessed August 24, 2011.

12. World Health Organization (WHO): Global Database on Body Mass Index 2011. http://apps.who.int/bmi/index.jsp, accessed August 24, 2011.

13. De Onis M, Blossner M: The World Health Organization database on child growth and malnutrition: methodology and applications. Int J Epidemiol 2003, 32:518-526.

14. World Health Organization (WHO): Nutrition Landscape Information Systems (NLIS). 2011. http://www.who.int/nutrition/nlis/en/, accessed August 24, 2011

15. Demographic and Health Surveys: Description of the Demographic and Health Surveys Individual Recode Data File. Measure DHS+, Version 1.0. Measure DHS+. 2008.

16. De Onis $M$, Blossner $M$, Borghi E: Prevalence and trends of stunting among pre-school children, 1990-2020. Public Health Nutr 2011, 14:1-7.

17. De Onis M, Blossner M, Borghi E, Frongillo EA, Morrois M: Estimates of global prevalence of child underweight in 1990 and 2010. JAMA 2004, 291(21):2600-2606

18. Coca-Cola: Annual Review 2008. Atlanta: Coca-Cola; 2008.

\section{doi:10.1186/1471-2458-14-1124}

Cite this article as: Wojcicki: The double burden household in sub-Saharan Africa: maternal overweight and obesity and childhood undernutrition from the year 2000: results from World Health Organization Data (WHO) and Demographic Health Surveys (DHS). BMC Public Health 2014 14:1124. 